\title{
The Clinical Features and Treatment Responses of Small Cell Lung Cancer Patients: A Single- Center Experience
}

\section{Küçük Hücreli Akciğer Kanserli Hastalarımızın Klinik Özellikleri ve Tedavi Yanıtları; Tek Merkez Deneyimi}

Mustafa Karaagac ${ }^{1}$,

Oguzhan Yildiz ${ }^{2}$

${ }^{1}$ Necmettin Erbakan University, Meram Faculty of Medicine, Department of Medical Oncology, Konya, Turkey

${ }^{2}$ Necmettin Erbakan University, Meram

Faculty of Medicine, Department of Internal Medicine, Konya, Turkey

Geliş Tarihi/Received: 02 December 2019 Kabul Tarihi/Accepted: 23 December 2019

Address correspondence to: Mustafa Karaagac, Necmettin Erbakan University, Meram Faculty of Medicine, Department of Medical Oncology, Konya, Turkey

e-mail: mustafakaraagac55@hotmail.com

ORCID

Mustafa Karaagac

https://orcid.org/0000 000345330620 OguzhanYildiz

https://orcid.org/0000 000240573108

\section{INTRODUCTION}

Lung cancer is the most common and fatal cancer, regardless of gender (1). Small cell lung cancer (SCLC) subtype, which accounts for approximately $15 \%$ of lung cancer cases, is less common than nonsmall cell subtypes but is associated with a more aggressive course and short survival (2). Although immunotherapy drugs, in addition to chemotherapy
(CT), have started to be used in SCLC treatment in developed countries, conventional CT is still the mainstay of treatment in most of the world (3).

However, the majority of information on $\mathrm{CT}$, as well as information on demographic data of patients, is based on studies from several decades ago. Besides, clinical observations suggest that current treatment approaches, patient adherence to treatment, and
Cite this article as:Karaagac M, Yildiz 0 . The Clinical Features and Treatmen Responses of Small Cell Lung Cancer Patients: A Single-Center Experience. Selcuk Med J 2020;36(1): 27-32
Disclosure: None of the authors has a financial interest in any of the products, devices, or drugs mentioned in this article. The research was not sponsored by an outside organization. All authors have agreed to allow full access to the primary data and to allow the journal to review the da if requested. 
treatment responses differ from previous decades. In this study, we aimed to determine the current demographic and clinical characteristics of our cohort and to determine their responses to the treatments.

\section{PATIENTS AND METHODS}

This was a single-center, retrospective, crosssectional, and cohort study. The study was performed according to the Declaration of Helsinki and approved by the Local Ethics Committee of the university (Local Ethics Committee approval number: 2019/2167). Since this was a retrospective file screening study, informed consent was not required.

In this study, the files of all patients with SCLC who treated and followed-up in our cancer center between July 1, 2009, and July 1, 2019, were evaluated without exception. The staging of all patients in this study was determined according to the 7th edition of the American Joint Committee on Cancer staging system. The response evaluation of the patients was done according to the Response Evaluation Criteria in Solid Tumors (RECIST) version 1.1. Patients who achieved a complete response (CR), partial response $(P R)$, and stable disease (SD) in accordance with RECIST were defined as 'responders'. In contrast, patients with progressive disease (PD) were identified as 'non-responders'. The Eastern Cooperative Oncology Group-Performance Score (ECOG-PS) was used to determine the performance status of the patients. ECOG-PS $\leq 2$ was named as 'good performance', whereas ECOG-PS $\geq 3$ was called as 'poor performance'.

Survival definitions consisted of the overall survival (TOS) and survival after metastasis (MOS). TOS was calculated as the time from the diagnosis to the date of death or last visit. And, MOS was calculated as the time from the diagnosis of metastasis to the date of death or last visit. All patients underwent TOS and MOS analysis.

Statistical analysis was performed by using SPSS version 22.0 (SPSS Inc., Chicago, IL, USA). A p-value $<0.05$ was required for statistical significance. Primary statistical analysis has included descriptive statistics of the patients. Descriptive statistics were calculated as proportions and medians. The Kaplan-Meier method was used for survival analysis. Log-Rank analysis was performed to compare the different subgroups. Univariate and multivariate Cox regression analyses were used to identify independent variables.

\section{RESULTS}

A total of 161 patients were assessed in this study. There were 151 males $(93.8 \%)$ and ten females $(6.2 \%)$. The median age at the time of diagnosis was 60.8 years (range; $30-86$ years). Eighteen patients $(11.2 \%)$ received primary CT and radiotherapy because of limited-stage. The number of metastatic patients at the time of diagnosis was 142 (88.2\%). Metastases were developed in an additional 12 patients, but seven patients never had a metastasis. Of the 154 metastatic patients, 104 had more than one organ or system metastasis. The details of the demographic and clinical parameters of patients are shown in Table 1.

The median TOS and median MOS were calculated as 15.7 months (0.03-106.97) and 13.79 months (0.03-79.54), respectively. Although they were metastatic, ten patients had never received first-line CT, and the median MOS was 1.88 months and 14.62 months, respectively, in those who did not receive CT and received CT. Twenty-one (18.9\%) of the 111 patients who needed second-line treatment did not receive CT, and the median MOS was 8.39 months and 18.45 months, respectively, in those who did not receive $\mathrm{CT}$ and received $\mathrm{CT}$. Eighteen of the 65 patients $(27.7 \%)$ who required the third-line treatment did not receive CT, and the median MOS was found to be 15.36 months and 23.86 months, respectively in those who did not receive CT and received CT. 31 patients $(19.3 \%)$ received the fourthline treatment, and six patients $(3.7 \%)$ received the fifth-line treatment.

Platinum-based CT regimens were applied in the first-line setting of treatment in almost all patients with extensive-stage. Platinum-free treatment regimens were preferred for subsequent lines of treatment. The details of the chemotherapies administered to the patients are described in table-2.

Although $72.2 \%$ of the patients who were treated for extensive-stage disease responded to the firstline treatment, the response rates to the treatments applied in the subsequent lines remained below $50 \%$. The details of the treatment responses of the patients are shown in table-3.

Poor performance status, presence of metastatic disease at the time of diagnosis, and refusal of treatment were detected as the univariate parameters affecting the median TOS. In multivariate analysis, the presence of metastatic disease at the time of diagnosis and refusal of treatment continued to be statistically significant. The details of the univariate parameters 
Table 1. The demographic and clinical parameters of patients

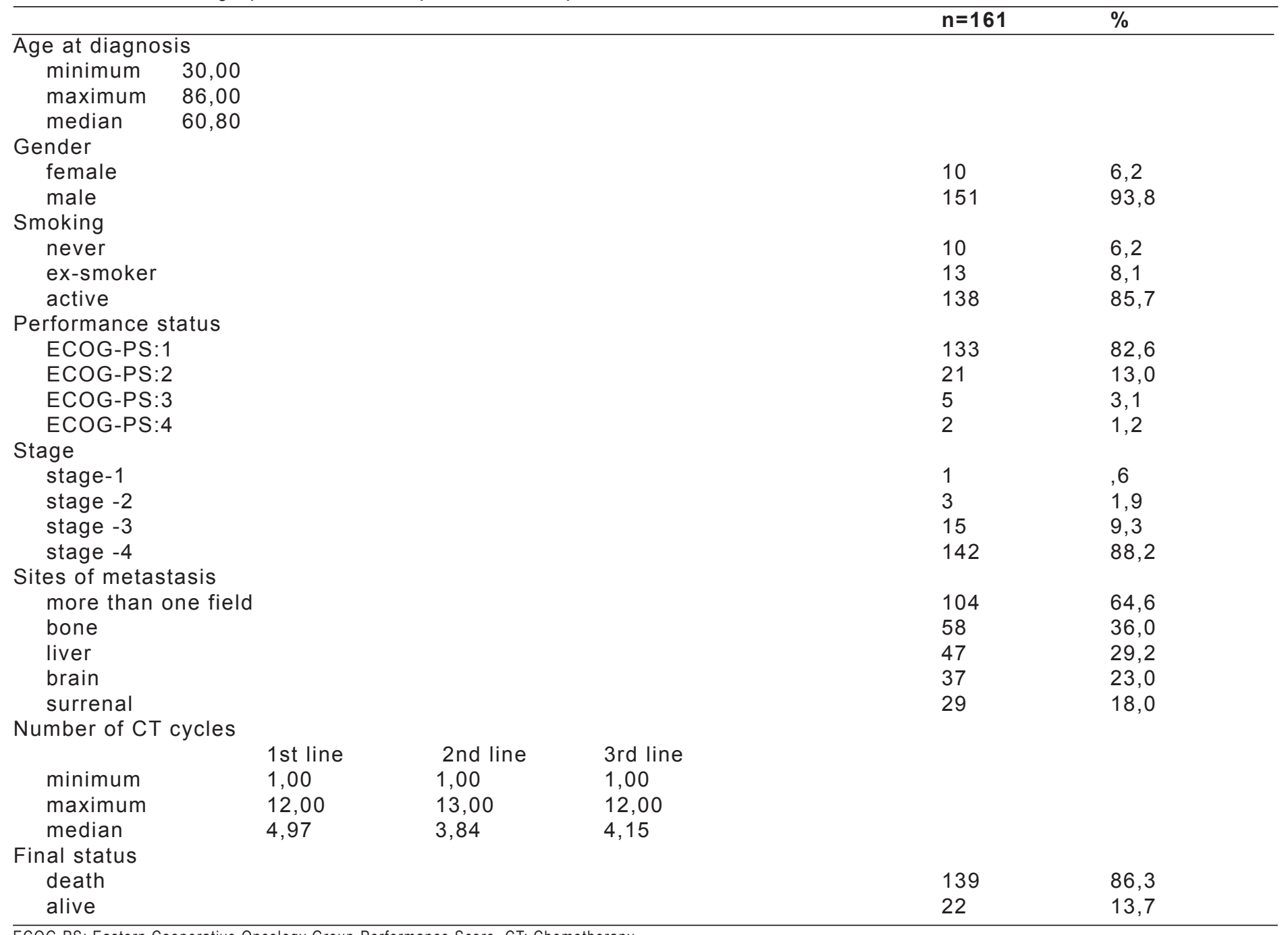

ECOG-PS: Eastern Cooperative Oncology Group-Performance Score, CT: Chemotherapy

affecting the median TOS are given in table-4. Poor performance status and refusal of treatment were detected as the univariate parameters affecting the median MOS. Moreover, these two parameters remained statistically significant in multivariate analysis. Please refer to table- 5 for details.

\section{DISCUSSION}

To the best of our knowledge, this is the only study on the clinical data of patients with SCLC in our country in the last decade. This is a critical study since it provides data on current treatment approaches, patient compliance, and treatment responses.

In this study, we demonstrated that the majority of patients with SCLC had a history of smoking, mostly male patients, a significant portion of the disease at the time of diagnosis was detected as an extensivestage, and most of the patients had metastases at more than one organ system. Also, we showed that the majority of patients responded to the first-line of treatment, but the response was unsustainable, and subsequent response rates were reduced. Moreover, we revealed that poor performance status and refusal of treatment were associated with decreased survival.

While SCLC constituted approximately $17 \%$ of all lung cancers in the 1980 s, this rate declined to approximately $12 \%$ in the early 2000 s. The main reason for this is the gradual decrease in smoking. However, smoking is still known as the most crucial factor in the etiology of this cancer (4). Almost all of our patients had a history of smoking. However, in contrast to the recent decline in the consumption of 
Table 2. The chemotherapy regimens and distribution of patients

\begin{tabular}{clll}
\hline & $\mathbf{n}$ & in group, \% & in all patients, \% \\
\hline 1st line CT & 154 & 100 & 95,7 \\
Not received & 10 & 6,5 & 6,2 \\
Received & 144 & 93,5 & 89,4 \\
cisplatin+etoposide & 124 & 86,1 & 77,0 \\
carboplatin+etoposide & 18 & 12,5 & 11,2 \\
monotherapy carboplatin & 1 &, 7 &, 6 \\
orally etoposide+cyclophosphamide & 1 &, 7 &, 6 \\
2nd line CT & 111 & 100,0 & 68,9 \\
Not received & 21 & 18,9 & 13,0 \\
Received & 90 & 81,1 & 55,9 \\
cisplatin+etoposide & 2 & 1,8 & 1,2 \\
cisplatin+vinorelbine & 1 &, 9 &, 6 \\
capecitabine+temozolomide & 1 &, 9 &, 6 \\
carboplatin+paclitaxel & 1 &, 9 &, 6 \\
carboplatin+etoposide & 3 & 2,7 & 1,9 \\
monoterapi karboplatin & 1 &, 9 &, 6 \\
cisplatin+irinotecan & 4 & 0,36 & 2,5 \\
CAVi & 34 & 30,6 & 21,1 \\
monotherapy topotecan & 21 & 18,9 & 13,0 \\
orally etoposide+cyclophosphamide & 14 & 12,6 & 8,7 \\
monotherapy etoposide & 3 & 2,7 & 1,9 \\
monotherapy irinotecan & 5 & 4,5 & 3,1 \\
3rd line CT & 65 & 100,0 & 40,4 \\
Not received & 18 & 27,7 & 11,2 \\
Received & 47 & 72,3 & 29,2 \\
monotherapy paclitaksel & 6 & 9,2 & 3,7 \\
monotherapy cyclophosphamide & 1 & 1,5 &, 6 \\
carboplatin+paclitaxel & 4 & 6,2 & 2,5 \\
carboplatin+etoposide & 1 & 1,5 &, 6 \\
cisplatin+irinotecan & 6 & 9,2 & 3,7 \\
CAVi & 9 & 13,8 & 5,6 \\
monotherapy topotecan & 8 & 12,3 & 5,0 \\
orally etoposide+cyclophosphamide & 7 & 10,8 & 4,3 \\
monotherapy etoposide & 1 & 1,5 & 6 \\
monotherapy irinotecan & 4 & 6,2 & 2,5 \\
\hline
\end{tabular}

CAVi: Cyclophosphamide+Adriamycin+Vincristine, CT: Chemotherapy

cigarettes in the general population, its use among women, especially in developed societies has been increasing recently, leading to an increased incidence of SCLC in younger women (5). Nevertheless, the fact that almost all of our patients consisted of men may be due to the older average age of our cohort and the low proportion of women who smoke in our society (6).
It has been shown that approximately two-thirds of patients with SCLC have an extensive-stage disease at the first diagnosis, and metastases are detected in multiple areas at the time of diagnosis. This is related to decreased survival (7). However, as in limited-stage disease, it is reported that better treatment responses and survival can be achieved when detected as oligometastatic disease, even if it is an extensive-

Table 3. The responses to chemotherapy

\begin{tabular}{llllll}
\hline & $\begin{array}{l}\text { Radiological } \\
\text { CR,\% }\end{array}$ & $\begin{array}{l}\text { Radiological } \\
\text { PR, \% }\end{array}$ & $\begin{array}{l}\text { Radiological } \\
\text { SD, } \%\end{array}$ & $\begin{array}{l}\text { Responder, \% } \\
\text { (CR/PR/SD) }\end{array}$ & $\begin{array}{l}\text { Non-responder, \% } \\
\text { (PD) }\end{array}$ \\
\hline 1st line CT & 9,0 & 37,5 & 25,7 & 72,2 & 27,8 \\
2nd line CT & 0 & 12,2 & 31,1 & 43,3 & 56,7 \\
3rd line CT & 0 & 10,6 & 29,8 & 40,4 & 59,6
\end{tabular}

CT: Chemotherapy, CR: Complete response, PR: Partial response, SD: Stable disease, PD: Progressive disease 
Table 4. The parameters affecting median overall survival

\begin{tabular}{|c|c|c|c|}
\hline \multicolumn{4}{|c|}{ Significant findings in the univariate regression analysis } \\
\hline & & P value & $95 \% \mathrm{Cl}$ \\
\hline poor performance status & & 0.019 & $10.33-14.36$ \\
\hline metastatic disease at the time of diagnosis & & 0.001 & $9.01-12.40$ \\
\hline refusal of 1 st line treatment & & 0.001 & $0.00-0.96$ \\
\hline refusal of 2 nd line treatment & & 0.001 & $6.98-8.85$ \\
\hline refusal of 3 rd line treatment & & 0.003 & $6.98-18.05$ \\
\hline \multicolumn{4}{|c|}{ Significant findings in the multivariate regression analysis } \\
\hline & Wald & P value & $95 \% \mathrm{Cl}$ \\
\hline metastatic disease at the time of diagnosis & 13.103 & 0.004 & $1.54-4.25$ \\
\hline refusal of $1 \mathrm{st}$ line treatment & 26.335 & $<0.001$ & $2.92-11.03$ \\
\hline refusal of 2 nd line treatment & 13.338 & $<0.001$ & $1.54-4.17$ \\
\hline refusal of 3 rd line treatment & 8.168 & 0.004 & $1.29-3.95$ \\
\hline
\end{tabular}

Cl: Confidence Interval

stage disease (8). Nevertheless, as in the literature, the majority of our patients consisted of extensivestage and poly-metastatic patients.

A partial improvement in the treatment results of limited-stage SCLC was achieved in the last four decades with $\mathrm{CT}$, co-administered radiotherapy, and additional prophylactic cranial irradiation $(9,10)$. However, the prognosis of SCLC is still worse. Patients with SCLC are usually responder to platinum-based treatment in the first-line setting, with a response rate of approximately $60-70 \%$ (11). This response rate was similarly demonstrated in our study. However, the response is not sustainable, and there is almost always a recurrence in the first two years. Besides, as a result of systemic metastases, the general health status of the patients gradually deteriorates $(12,13)$. Ultimately, despite treatment, the majority of patients die within one year (14). The findings herein we demonstrated are consistent with this issue. Our patients also well-responded to the first-line treatment, and as expected, this response was not sustainable. However, survival was approximately $20 \%$ longer in our patients than in the literature.

The majority of patients with extensive-stage SCLC can only receive two lines of treatment (15). Although it has been shown that maintenance/consolidation CT may be useful to improve survival, the third-line and beyond lines treatments for SCLC are controversial $(15,16)$. Only one-quarter of our patients were able to receive the third-line of treatment. However, it is essential that the response rates to the third-line treatment of our cohort were excellent and that receiving third-line treatment led to a statistically significant increase in survival. Also, it is highly probable that approximately $20 \%$ longer median survival in our patients was due to this condition. In our opinion, these results are especially important for countries with a meager health budget. Because, when the current literature on the treatment os SCLC is examined, it is seen that the data related to

Table 5. The parameters affecting median survival after metastasis

\begin{tabular}{|c|c|c|c|}
\hline \multicolumn{4}{|c|}{ Significant findings in the univariate regression analysis } \\
\hline $\begin{array}{l}\text { poor performance status } \\
\text { refusal of } 1 \text { st line treatment } \\
\text { refusal of } 2 \text { nd line treatment } \\
\text { refusal of } 3 \text { rd line treatment }\end{array}$ & & $\begin{array}{l}0.039 \\
<0.001 \\
<0.001 \\
0.007\end{array}$ & $\begin{array}{l}8.88-12.54 \\
0.00-0.97 \\
6.95-8.22 \\
6.98-18.05\end{array}$ \\
\hline \multicolumn{4}{|c|}{ Significant findings in the multivariate regression analysis } \\
\hline $\begin{array}{l}\text { poor performance status } \\
\text { refusal of } 1 \text { st line treatment } \\
\text { refusal of } 2 \text { nd line treatment } \\
\text { refusal of } 3 \text { rd line treatment }\end{array}$ & $\begin{array}{l}9.462 \\
43.131 \\
27.367 \\
7.026\end{array}$ & $\begin{array}{l}0.051 \\
<0.001 \\
<0.001 \\
0.008\end{array}$ & $\begin{array}{l}1.32-4.48 \\
5.01-19.70 \\
2.38-6.75 \\
0.27-0.82\end{array}$ \\
\hline
\end{tabular}

Cl: Confidence Interval 
traditional CT applications are replacing with the data of economically expensive immunotherapy regimens $(17,18)$. However, despite all these high costs, the median survival is not far beyond the results that we presented here. Considering that the majority of the patients received only two line treatments in most of the world and that most of the cancer centers did not use the third-line treatments, our results showed that it is absolutely necessary to keep in mind the recommendation of third-line treatment for tolerable patients.

As in patients with non-small cell lung cancer, poor performance status is a factor that adversely affects survival in patients with $\operatorname{SCLC}(19,20)$. It was confirmed in our study that poor performance status is an adverse prognostic factor. The limitations of this study are that the retrospective design, the lack of randomization, relatively low number of patients, and the lack of data on adverse effects due to the treatments.

\section{CONCLUSIONS}

In this study, it was confirmed that early diagnosis of SCLC is associated with a survival advantage. Although the current CT regimens in the treatment of SCLC are not curative, the results of our study were demonstrated that the patients who received and were able to tolerate the treatment had obtained a survival advantage, regardless of the disease phase. Further prospective studies with a larger number of patients are needed to validate these results.

Conflict of interest: Authors declare that there is no conflict of interest between the authors of the article.

Financial conflict of interest: Authors declare that they did not receive any financial support in this study.

Address correspondence to: Mustafa Karaagac, Necmettin Erbakan University, Meram Faculty of Medicine, Department of Medical Oncology, Konya, Turkey

Telephone: 0090 3322237806, 5057455812 (GSM)

E-mail: mustafakaraagac55@hotmail.com

\section{REFERENCES}

1. Siegel RL, Miller KD, Jemal A. Cancer statistics, 2019. CA Cancer J Clin 2019;69(1):7-34.

2. Inamura K. Lung cancer: Understanding its molecular pathology and the 2015 WHO Classification. Front Oncol 2017;7:1-7.

3. Waqar SN, Morgensztern D. Treatment advances in small cell lung cancer (SCLC). Pharmacol Ther 2017;180:16-23.

4. Govindan R, Page N, Morgensztern D, et al. Changing epidemiology of small-cell lung cancer in the United
States over the last 30 years: Analysis of the surveillance, epidemiologic, and end results database. J Clin Oncol 2006;24(28):4539-44.

5. Jemal A, Miller KD, Ma J, et al. Higher lung cancer incidence in young women than young men in the united states. $\mathrm{N}$ Engl J Med 2018;378(21):1999-2009.

6. Doğanay S, Sözmen K, Kalaça S, et al. Türkiye'de toplumda sigara içme sıklığı nasıl değişiyor?. Turkish Journal of Public Health 2012;10(2):93-115.

7. Byers LA, Rudin CM. Small cell lung cancer: Where do we go from here? Cancer 2015;121(5):664-72.

8. Shirasawa M, Fukui $T$, Kusuhara $S$, et al. Prognostic differences between oligometastatic and polymetastatic extensive disease-small cell lung cancer. PLoS One 2019;14(4):e0214599.

9. Jänne PA, Freidlin B, Saxman S, et al. Twenty-five years of clinical research for patients with limited-stage small cell lung carcinoma in North America. Cancer 2002; 95(7):1528-38.

10. Jett JR, Schild SE, Kesler KA, et al. Treatment of small cell lung cancer: Diagnosis and management of lung cancer, 3rd ed: American College of Chest Physicians evidence-based clinical practice guidelines. Chest 2013;143(5 Suppl):e400Se419s.

11. Simon M, Argiris A, Murren JR. Progress in the therapy of small cell lung cancer. Crit Rev Oncol Hematol 2004; 49(2):119-33.

12. Bernhardt EB, Jalal SI. Small cell lung cancer. Cancer Treat Res 2016;170:301-22.

13. Gong J, Salgia R. Managing patients with relapsed small-cell lung cancer. J Oncol Pract 2018;14(6):359-66.

14. Asai N, Ohkuni $\mathrm{Y}$, Kaneko N, et al. Relapsed small cell lung cancer: Treatment options and latest developments. Ther Adv Med Oncol 2014;6(2):69-82.

15. Simos D, Sajjady G, Sergi M, et al. Third-line chemotherapy in small-cell lung cancer: An international analysis. Clin Lung Cancer 2014;15(2):110-8.

16. Bozcuk H, Artac M, Ozdogan M, et al. Does maintenance/ consolidation chemotherapy have a role in the management of small cell lung cancer (SCLC)? A metaanalysis of the published controlled trials. Cancer 2005;104(12):2650-7.

17. Paz-Ares L, Dvorkin M, Chen Y, et al. CASPIAN investigators. Durvalumab plus platinum-etoposide versus platinumetoposide in first-line treatment of extensive-stage small-cell lung cancer (CASPIAN): A randomised, controlled, openlabel, phase 3 trial. Lancet 2019. pii: S0140-6736(19)322226.

18. Horn L, Mansfield AS, Szczęsna A, et al. IMpower133 Study Group. First-Line Atezolizumab plus Chemotherapy in Extensive-Stage Small-Cell Lung Cancer. N Engl J Med 2018;379(23):2220-9.

19. Inal $A$, Karakuş $A$, Kaplan $M A$, et al. Küçük hücreli dışı akciğer kanserinde prognostik faktörler. Selçuk Tıp Derg 2013;29(1):5-8.

20. Reck M, Thatcher N, Smit EF, et al. Baseline quality of life and performance status as prognostic factors in patients with extensive-stage disease small cell lung cancer treated with pemetrexed plus carboplatin vs. etoposide plus carboplatin. Lung Cancer 2012; 78(3):276-81. 